\title{
UK Public Understanding of Unconscious Bias and Unconscious Bias Training
}

\author{
Magda Osman \\ Department of Psychology, School of Biological and Chemical Sciences, Queen Mary University of London, London, UK \\ Email: m.osman@qmul.ac.uk
}

How to cite this paper: Osman, M. (2021) UK Public Understanding of Unconscious Bias and Unconscious Bias Training. Psychology, 12, 1058-1069.

https://doi.org/10.4236/psych.2021.127063

Received: June 9, 2021

Accepted: July 13, 2021

Published: July 16, 2021

Copyright (C 2021 by author(s) and Scientific Research Publishing Inc. This work is licensed under the Creative Commons Attribution International License (CC BY 4.0).

http://creativecommons.org/licenses/by/4.0/

\begin{abstract}
This study examines the public understanding of unconscious bias and training methods addressing so as to determine the extent to which it aligns with scientific evidence on both. The findings from a pilot survey on a UK sample $(\mathrm{N}=200)$. In the main, public opinion of unconscious bias and the training out of it shows aspects of misalignment with current psychological evidence. Also, the survey reveals that political affiliation and estimates of efficacy of unconscious bias training predict the favourability of opinions towards unconscious bias training. This work provides new insights into where efforts might need to be made to manage expectations in organisations in which unconscious bias training is implemented, and a greater need to communicate scientific insights that accurately convey the current limitations of the efficacy of unconscious bias training.
\end{abstract}

\section{Keywords}

Unconscious Bias, Unconscious Bias Training, Equality Diversity and Inclusion, Public Opinion, Implicit Association Test

\section{Introduction}

Diversity, equality and inclusion (DEI) varies in what it specifically refers to. There are discussions as to whether it ought to be delineated from anti-discriminatory approaches, and should be exclusively considered as a type of initiative to address equal opportunities. Others have proposed that it be viewed as a way of maximising talent pools by diversifying to ensure greater inclusion of those underrepresented in the workforce (Oswick \& Noon, 2014). Whatever the specific definition of DEI, two critical factors worth highlight here. First, that DEI training is a sizable industry, generating an estimated 8 billion dollars a year in the US alone (Kirkland \& Bohnet, 2017). The second is that it is an unregulated in- 
dustry (Newkirk, 2019), and this means that there are no standards for determining the quality of DEI training programmes, and no standards for evaluating and assessing the performance of DEI training programmes. To date there is limited work investigating public understanding of DEI training and expectations around the efficacy of the training methods, which the present study aims to address by focusing specifically on an example of DEI training: Unconscious Bias training. The remainder of the introduction will discuss the issues around unconscious bias training, and the evidence evaluating it, so as to provide context for why it is also important to gauge public understanding of unconscious bias training.

Unconscious Bias Training: The Basics. Included in the range of practices used for DEI programmes is unconscious bias training (Noon, 2018). This form of training is typically divided into two parts. The first is to use a psychological test (e.g. Implicit association test [IAT]-Greenwald et al., 1998) to reveal to those taking part in the training their levels of unconscious bias towards protected values (e.g. age, gender, sexual orientation, ethnicity). The second is to use a variety of approaches to mitigate the presence of bias so as to promote positive attitudes and interactions with those in the workplace that might be the recipients of bias. For instance, if managers are made more aware of their unconscious biases that might prevent those from protected values from prospering in the workplace, then unconscious bias training can, in theory, help reduce discriminatory practices (Carter et al., 2020). Thus, the common idea here is that raising awareness of latent biases, and increasing knowledge of the presence of biases will reduce biases, and in turn any discriminatory behaviours that are also present in the workplace.

Practitioners of DEI training methods are in demand from private and public sectors to help with improving workplace practices. So, in turn, there are increased efforts to develop an evidence base that demonstrates what aspects of DEI training reliably improves the workplace based on objective metrics. So, one place to look for evidence is the psychological literature on which unconscious bias training bases its techniques around. Before doing this, it is worth spelling out some of the assumptions that need to be met given the logic of unconscious bias training.

The assumptions needed to support the use of unconscious bias training.

1) There is a dissociation between conscious and unconscious processes, where unconscious processes are inaccessible to conscious inspection.

2) The Implicit association test (IAT) is a reliable and valid measure of unconscious bias.

3) Scores on the IAT predict observable behaviour above and beyond explicit measures of personal attitudes and beliefs.

4) Awareness of biases and the causes of biases presented explicitly through coaching during unconscious bias training sessions is an effective way of reducing unconscious bias, and in turn reducing unconscious bias will reduce the behavioural expression of that bias (e.g. discriminatory behaviour) through mean- 
ingful objective measures.

5) The IAT can be used as an objective diagnostic tool to show the reduction of unconscious biases post unconscious bias training.

IAT: The Issues. First, it is worth highlighting that the IAT suffers several key problems (for discussion see, Jost, 2019), however to keep this focused, the discussion here will be examining evidence that speaks to assumptions 2, 3 and 5; for a detailed analysis of assumption 1, see Osman (2014) and Newell and Shanks (2014), and assumption 4 will be discussed in the next section.

First, there is very limited test-retest reliability (Gawronski et al., 2017). What this means is that the relationship is very low between an individual's score taking an IAT at one time, and then repeating the test at a later time. What this also implies is that, either the biases aren't stable over time, or the test doesn't reliably measure what it purports to measure, or potentially both depending on how sceptical one is about the status of unconscious bias as a phenomenon. The former interpretation is against common dual theorists' claims given the general distinctions between two systems one fast and unconscious and the second slow and conscious (for critical discussion see Osman, 2014). Most flavours of dual process theory would propose that unconscious biases are stable and preserve over time, especially given that they are built up over the lifetime of the individual and aren't consciously accessible to be changed easily. The latter interpretation raises questions regarding the IAT and whether it should be used as a means of diagnosing the presence of unconscious biases, and as an objective measure of the impact of unconscious bias training post implementation to detect the reduction of the presence of an unconscious bias (assumption 5).

The second problem is that the IAT doesn't appear to be reliably predictive of actual behaviours (Oswald et al., 2013, 2015; Rezaei, 2011). To the extent that the IAT might even detect unconscious biases, which from the earlier discussion is already under contention, the IAT doesn't predictable discriminatory behaviours. This issue is particularly problematic for EDI training programmes for the reason that if the IAT doesn't reliably detect unconscious biases, and doesn't predict objective behaviours that might be assumed to be causally associated with harbouring unconscious biases towards a particular group, then it also cannot be used as an objective test of the efficacy of unconscious bias training.

Unconscious Bias Training: The Issues. Moving away from empirical work examining the IAT, there is also considerable work examining unconscious bias training itself, and the discussion here will focus on what support there is for assumption 4. Empirical investigations have been conducted from both basic and applied scientific psychological approaches (e.g. FitzGerald et al., 2019; Gawronski et al., 2017; Jost, 2019; Oswald et al., 2013, 2015; Skov, 2020; Rezaei, 2011). The general conclusions from this work are that there are deep problems with unconscious bias training (e.g., Carter et al., 2020; Dobbin et al., 2011; Noon, 2018). Several studies have examined the extent to which unconscious bias training itself leads to any objective changes in the work practices of those exposed to the training; this is critical to addressing assumption 4 . The findings 
suggest that unconscious bias training had no impact at all (Behavioural Insights Team, 2020; Chang et al., 2019; Duguid \& Thomas-Hunt, 2015). Worse still, it is also liable to producing backfiring effects, particularly if the training is made mandatory (Carter et al., 2020; Dobbin \& Kalev, 2018).

Motivation for present study: Given the various assumptions that would need to be evidenced in order to support the use of unconscious bias training, there appears to be a significant lack of reliable evidence in support for most of them. Nonetheless, in most organisations (private and public) it is mandatory (Carter et al., 2020; Newkirk, 2019), and there has been considerable discussion of unconscious bias in news media. For instance, in UK broadsheets (Sayal, 2020; Forrest, 2020; Blakely, 2020; Fisher, 2020), news broadcasting (Coughlan, 2020) as well as magazines (Forbes, 2020) there have been discussions regarding the scrapping of unconscious bias training in public sector organisations (Government UK, 2020). While it is clear that the theme of unconscious bias training is in the public eye, there has been limited work examining what the public understanding of unconscious bias is, and in turn opinions on efforts to reduce it through unconscious bias training.

Given that the state of the scientific evidence suggests that there are concerns around its efficacy, it is of interest to the scientific community and practitioners of DEI training methods to understand what the general views and opinions the public hold on the concept of unconscious bias, and their attitudes towards unconscious bias training. Therefore, the aim of this pilot survey it to advance understanding of public opinion on these matters, and to investigate where there is alignment and misalignment with scientific insights on the topic of unconscious bias and training out of it.

\section{Method}

Participants: The survey was conducted online via Qualitrics an online survey platform (https://www.qualtrics.com), and participants $(\mathrm{N}=200)$ were sampled from Prolific Academic a crowd sourcing website (http://www.prolific.co/). Participants were currently UK residents, that were born in the UK, with their first language being English. Table 1 presents the demographic details of the sample. Participants were compensated for their time in taking part $(£ 0.95 ; \$ 1.31)$; the length of time to complete the survey was on average approximately 3.9 minutes $(\mathrm{SD}=1.4$ minutes). The survey received Queen Mary University of London College ethics approval (QMREC194), and consent was required before taking part in the survey.

Procedure: The survey consisted of 5 demographic questions that required participants report their age, their self-identified sex (male, female), level of education (non-university education, university education), religiosity (not religious, religious), and political affiliation (no affiliation, liberal/labour, centrist, conservative/right). Then they were presented two further sets of questions, 3 regarding questions referred to unconscious bias, and 3 regarding questions referring to unconscious bias training. The questions and the response options are presented in Table 2. 
Table 1. Demographic details.

\begin{tabular}{|c|c|c|c|c|c|}
\hline \multirow{2}{*}{$\begin{array}{c}\text { Gender } \\
\text { Age }\end{array}$} & \multirow[b]{2}{*}{ Means } & \multicolumn{2}{|c|}{ Male $(\mathrm{N}=86) 43 \%$} & \multicolumn{2}{|c|}{ Female $(\mathrm{N}=114) 57 \%$} \\
\hline & & $\mathrm{M}=36.94$ & $(\mathrm{SD}=12.75)$ & $\mathrm{M}=36.42$ & $(\mathrm{SD}=11.76)$ \\
\hline & Range & \multicolumn{2}{|c|}{18 years to 65 years } & \multicolumn{2}{|c|}{20 years to 66 years } \\
\hline \multirow{3}{*}{ Education } & Prefer not to say & $(\mathrm{N}=7)$ & $8.1 \%$ & $(\mathrm{~N}=7)$ & $6.1 \%$ \\
\hline & Non University & $(\mathrm{N}=27)$ & $31.4 \%$ & $(\mathrm{~N}=40)$ & $35.1 \%$ \\
\hline & University & $(\mathrm{N}=52)$ & $60.5 \%$ & $(\mathrm{~N}=67)$ & $58.8 \%$ \\
\hline \multirow{3}{*}{ Religiosity } & Prefer not to say & $(\mathrm{N}=0)$ & $0 \%$ & $(\mathrm{~N}=0)$ & $0 \%$ \\
\hline & Not Religious & $(\mathrm{N}=64)$ & $74.4 \%$ & $(\mathrm{~N}=73)$ & $64 \%$ \\
\hline & Religious & $(\mathrm{N}=22)$ & $25.6 \%$ & $(\mathrm{~N}=41)$ & $36 \%$ \\
\hline \multirow{4}{*}{ Politics } & None & $(\mathrm{N}=29)$ & $33.7 \%$ & $(\mathrm{~N}=34)$ & $29.8 \%$ \\
\hline & Labour/Liberal & $(\mathrm{N}=23)$ & $26.7 \%$ & $(\mathrm{~N}=37)$ & $32.5 \%$ \\
\hline & Centrist & $(\mathrm{N}=10)$ & $11.6 \%$ & $(\mathrm{~N}=9)$ & $7.9 \%$ \\
\hline & Conservative/Right & $(\mathrm{N}=24)$ & $27.9 \%$ & $(\mathrm{~N}=34)$ & $29.8 \%$ \\
\hline
\end{tabular}

Table 2. Questions for Set 1 (unconscious bias) and Set 2 (unconscious bias training).

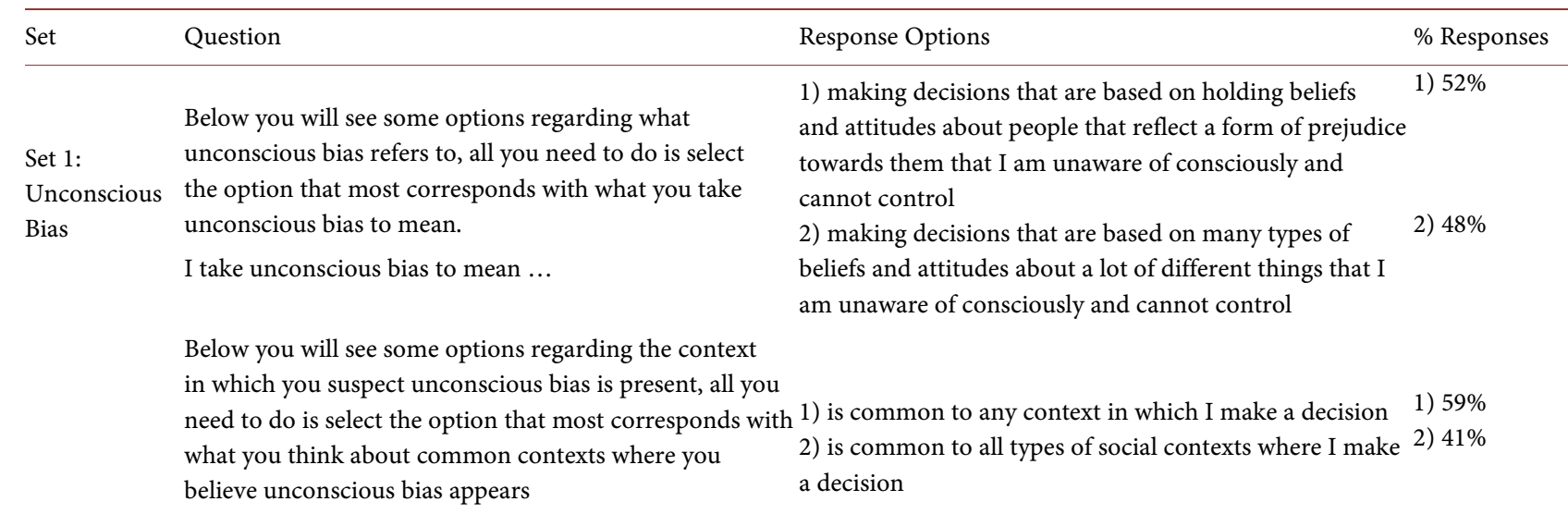

Unconscious bias ...

Below you will see some options regarding how common you think unconscious bias given the context that you think it occurs in, all you need to do is select the option that most corresponds with how prevalent you think

1) is present rarely when I make a decision unconscious bias is in social contexts you make decisions

2 ) is present some of the times I make a decision in,

3 ) is present every time I make a decision

3) $31 \%$

I believe unconscious bias ...

Below you will see some options regarding what Set 2: $\quad$ unconscious bias training refers to, all you need to do is Unconscious select the option that most corresponds with what you Bias training take unconscious bias to mean.

Unconscious bias training means ...

All you need to do here is select which option corresponds to you
1) Helping me to understand, in general, using psychological methods, the types of unconscious biases that all people have and revealing ways to avoid unconscious bias

2) Helping me to understand specifically, using psychological methods, the types of unconscious biases that I have and revealing ways to avoid unconscious bias

3) I have been on an unconscious bias training course

4) I have NOT been on an unconscious bias training 2) $89.5 \%$ course 
Below you will see some options regarding the extent to which you anticipate the effectiveness of unconscious bias training
1) I do NOT believe I have unconscious biases that need to be addressed through unconscious bias training

2) I believe it will not impact the presence of my unconscious biases

3) I believe it will help me to reduce my unconscious biases

4) I believe it will help me to eliminate my unconscious biases

1) I do not believe that unconscious bias training is necessary and there are no social issues that need to be addressed

2) I do not believe that unconscious bias training is necessary to address social issues and it is not based on sound psychological theory and evidence

Please select from the options below the option that best reflects you opinion on unconscious bias training
3) I do not believe that unconscious bias training is necessary to address social issues even if it is based on sound psychological theory and evidence

4) I believe that unconscious bias training is necessary to address social issues but is not yet based on sound psychological theory and evidence

5) I believe that unconscious bias training is necessary to address social issues and is based on sound psychological theory and evidence
1) $13.5 \%$

2) $31 \%$

3) $52 \%$

4) $3.5 \%$

1) $5 \%$

2) $6.5 \%$

3) $13 \%$

4) $27.5 \%$

5) $48 \%$

\section{Results and Discussion}

Unconscious Bias: Overall the findings from the pilot survey which are presented in Table 1 suggest that over half view unconscious bias as a general phenomenon (52\%) and that it is presented in most contexts (59\%), and that unconscious bias is prevalent sometimes (57\%) rather than rarely (12\%) or all the time (31\%). What we can take from this pattern of results is that the majority view is that unconscious bias shapes day to day decisions in all manner of contexts. But, there is still a large minority of respondents that treat unconscious bias as something that is specifically social in nature, and specifically found in social interactions. In either case, unconscious bias is not judged to be something that is occurring at all the time.

Unconscious Bias Training: Turning to unconscious bias training itself, the vast majority of the sample (89.5\%) have not received any training. Regardless of whether the sample had received training or not, the majority believed that it was designed to help understanding of unconscious bias regarding all people (61.5\%) rather than help address their own specific biases (38.5\%).

When it comes to the efficacy of the training, the dominant opinion overall was that it would reduce unconscious biases (52\%). If split by those exposed and not exposed to training, in the former case $52 \%$ expected training to reduce their unconscious biases, and for the latter 52\% thought it would reduce their unconscious biases. Thus, the findings here indicate that, irrespective of prior experience with the training, judged efficacy in general was the majority opinion. By contrast, $31 \%$ of the sample that hadn't received training expected it not to work, 
and $33 \%$ that had received didn't expect it to work. Conversely, 3\% of those that hadn't received training believed it would eliminate their biases, and $1 \%$ that had received believed it would eliminate their unconscious biases.

The sample were also asked about their general opinions on unconscious bias training and whether or not it was necessary to help address societal issues based on whether the psychological theory and evidence on which it was based was sound, or not. $5 \%$ revealed that unconscious bias training was neither necessary or that there were societal issues that needed addressing. $6.5 \%$ indicated that the training was neither necessary and not based on sound psychological theory and evidence. Also, 13\% revealed it wasn't necessary to address societal issues even if it were based on sound psychological theory and evidence. For favourable opinions, $27.5 \%$ thought it necessary to address societal issues but that the training is not yet based on sound psychological theory and evidence, and $48 \%$ thought it necessary to address societal issues and is based on sound psychological theory and evidence. What seems to be the case here is that the majority of the sample indicated the most favourable opinion towards unconscious bias training.

Individual Differences: A regression analysis examined the general opinion people had of unconscious bias training, with the predictors as age, gender, education level, religiosity, and political affiliation, responses to the meaning of unconscious bias, context in which unconscious bias occurs, frequency of unconscious bias, meaning of unconscious bias training, experience of unconscious bias training, and effectiveness of unconscious bias training. Overall, the predictors accounted for $27 \%$ of the variance in opinions on unconscious bias training. $\mathrm{F}(11,198)=7.42, p<.0005$. Political affiliation negatively predicted opinions in the direction that the more affiliation shifted towards a liberal leaning affiliation the more favourable opinions were towards unconscious bias training $(\mathrm{t}=-3.36$, $\beta=-.21, p<.005)$. The more effective unconscious bias training was judged to be, the more favourable opinions towards unconscious bias training were $(\mathrm{t}=$ $6.33, \beta=.41, p<.00005)$. No other predictors were significant.

Looking more specifically at the break down of political affiliation and associated general opinions of unconscious bias training, for the most favourable option selected (i.e. unconscious bias training is necessary to address societal issues and is based on sound theory and evidence), the breakdown is as follows: no party affiliation (43\%), labour/liberal (63\%), centrist (52\%) and conservative/right (36\%). Conversely, for the opinion indicating that unconscious bias training was neither necessary to address societal issues or based on sound theory and evidence, the breakdown is as follows: no party affiliation (3\%), labour/liberal (10\%), centrist (5\%) and conservative/right (16\%). Overall, this significant pattern suggests that moving more towards conservative political party affiliation reduces positive opinions of unconscious bias training and increases towards negative opinions of it.

Finally, the correspondence between judged efficacy of unconscious bias training and opinions of it indicates that, those that are of the opinion that uncon- 
scious bias training was necessary to address societal values and based on sound psychological theory and evidence expect that it will either reduce $(66 \%)$ or eliminate their unconscious biases (67\%). The proportion was much lower for those that didn't expect it to work (29\%) or don't think they had unconscious biases and so don't need training (18\%). This pattern indicates that as expectance for unconscious bias training to work increases, the most favourable opinion of unconscious bias training is held.

\section{General Discussion}

The results of the pilot survey provide insights into two critical areas in which the public differs from scientific evidence on their understanding of unconscious bias and unconscious bias training. First, just under half of the sample takes unconscious bias to refer to a psychological phenomenon that specifically impacts their decision-making around people, and is present in social contexts. While not the majority opinion, a large minority hold views at odds with psychological literature for which unconscious bias is attributed to any context. Unconscious bias is claimed to be a pervasive phenomenon (Epstein, 1994; Gawronski, 2019; Gigerenzer, 1991; Kahneman, 2011), and generally refers to the overextension of prior learnt knowledge, where it is preferentially weighed at the expense of other more relevant and accurate information. One reason that the public many attribute unconscious bias to social contexts specifically might be because of narrow media discussions of it which only discusses biases that are held against protected values (Coughlan, 2020; Forbes, 2020; Sayal, 2020; Forrest, 2020; Blakely, 2020; Fisher, 2020).

Also of note is the distinction between how prevalent unconscious biases are judged to be by the sample and by academic literature. The common response from the sample was that unconscious biases occur sometimes, with few selecting all the time or rarely options. Recent work, albeit in the domain of forecasting attempted to determine the frequency with which unconscious bias is present in a sample of 500 professionals (Karelse, 2021). While the study didn't examine the frequency of how often biases are recruited to inform decisions, it did attempt to determine the prevalence of 16 specific cognitive biases in the sample of professionals. Of the various biases examined, between $66 \%$ to $90 \%$ of the sample tended to exhibit the biases, which indicates that prevalence within a sample is fairly high. To things to highlight here are, first that a variety of biases that are cognitive are characterised as unconscious bias. Second, while the study refers to the cognitive biases as unconscious, it did not actually investigate whether the process behind generating a biased response was unconscious. This means that the presentation of findings provides a distorted picture of the prevalence of biases within a population, because the phenomenon being examined are not referred to correctly. This has implications for the communication of scientific findings, which in turn impacts the accuracy of reporting of scientific findings in news media, and public understanding of current evidence on 
biases through news media.

The second area of misalignment concerns the efficacy of unconscious bias training. While the majority of the public have yet to be exposed to it, irrespective of experience with it, the majority also believed that the training would reduce their unconscious biases. This is clearly at odds with the current empirical literature. Though here the opinions are somewhat nuanced. When viewed together with the favourability of unconscious bias training, the less the training is expected to work the less favourable the opinions are regarding whether it is necessary to address societal issues and is based on sound psychological theory and evidence.

In addition, individual differences also play a role, where political affiliation predicts favourability towards unconscious bias training. Those that are affiliated with liberal/labour political parties are most positively disposed, and those affiliated with conservative/right political parties are the least positively disposed.

What implications do these findings have for the scientific community and practitioners of DEI approaches? When it comes to unconscious bias, understanding that it is part and parcel of our cognitive functioning would mean it is better aligned with scientific studies of the phenomenon. While it doesn't take away from the need to improve our day-to-day judgments and decisions by avoiding reliance on biased thinking, an important to highlight is that biases are accessible to us, and we have the capacity to address them (Gawronski, 2019). Understanding more about the types of biases we face and the psychological basis of them is important in general, as well as in specific professional contexts. Thus, more scientific engagement with the public to promote a better understanding of biases (unconscious or otherwise) and why they are part of our cognitive functioning would be a generally useful endeavour, so long as the scientific evidence is presented accurately as was highlighted earlier.

Moreover, putting biases in context of general aspects of our cognitive function can also help to improve DEI training initiatives. By focusing on basic cognitive biases rather than specific social biases, can serve several useful functions, including decreasing inter-group tensions amongst those on DEI training methods. Here the evidence suggests that, in DEI training initiatives such as unconscious bias training, identifying a group that holds unconscious biases towards another group, can lead to backfiring effects, such as increased tensions between different groups. In addition, incorporating current psychological theory and empirical evidence on biases helps to increase opportunities to make DEI training scientifically driven. Taking this kind of approach has also been speculated to lead to more effective outcomes of DEI training programmes (Carter et al., 2020; Civitillo et al., 2018; Dobbin \& Kalev, 2018). Moreover, increasing efforts to conduct initial cognitive testing of the workforces' current attitudes and perceptions of bias and levels of inclusion, before any training initiatives are introduced, helps uptake of the training, because it is tailored specifically to the needs of the organization. As this pilot study hopefully shows, people can vary with 
respect to several core interpretations of core concepts, such as bias. If DEI methods, such as unconscious bias training are to be used, then it is important to recognise that recipients of the training ought not to be treated as a homogenous group with similar attitudes and opinions towards the training or their views on biases and where and how they appear. Finally, given that the biggest disconnect is between the evidence base regarding unconscious bias training and the public's view of its efficacy, clearly this needs to be addressed. Better alignment is needed in order to manage expectations. If a workforce reflects similar views as those indicated in the present study, then they will expect positive changes in workplace environments following unconscious bias training, which to date, does not match with what the scientific evidence base suggests.

\section{Conflicts of Interest}

The author declares no conflicts of interest regarding the publication of this paper.

\section{References}

Behavioural Insights Team (2020) Unconscious Bias and Diversity Training-What the Evidence Says.

https://assets.publishing.service.gov.uk/government/uploads/system/uploads/attachme nt_data/file/944431/20-12-14_UBT_BIT_report.pdf

Blakely, R. (2020). I've Confronted My Unconscious Bias but Will It Change a Thing? Times UK. Times UK. Retrieved July, 11, 2020.

https://www.thetimes.co.uk/article/rhys-blakely-ive-confronted-my-unconscious-biasbut-will-it-change-a-thing-025zfgmhc

Carter, E. R., Onyeador, I. N., \& Lewis Jr., N. A. (2020). Developing \& Delivering Effective Anti-Bias Training: Challenges \& Recommendations. Behavioral Science \& Policy, 6, 57-70. https://doi.org/10.1353/bsp.2020.0005

Chang, E. H., Milkman, K. L., Gromet, D. M., Rebele, R. W., Massey, C., Duckworth, A. L., \& Grant, A. M. (2019). The Mixed Effects of Online Diversity Training. Proceedings of the National Academy of Sciences of the United States of America, 116, 7778-7783. https://doi.org/10.1073/pnas.1816076116

Civitillo, S., Juang, L. P., \& Schachner, M. K. (2018). Challenging Beliefs about Cultural Diversity in Education: A Synthesis and Critical Review of Trainings with Pre-Service Teachers. Educational Research Review, 24, 67-83. https://doi.org/10.1016/j.edurev.2018.01.003

Coughlan, S. (2020). Unconscious Bias Training' to Be Scrapped by Ministers. BBC online. Retrieved 15, December, 2020. https://www.bbc.co.uk/news/education-55309923

Dobbin, F., \& Kalev, A. (2018). Why Doesn't Diversity Training Work? The Challenge for Industry and Academia. Anthropology Now, 10, 48-55. https://doi.org/10.1080/19428200.2018.1493182

Dobbin, F., Kim, S., \& Kalev, A. (2011). You Can't Always Get What You Need: Organizational Determinants of Diversity Programs. American Sociological Review, 76, 386-411. https://doi.org/10.1177\%2F0003122411409704

Duguid, M. M., \& Thomas-Hunt, M. C. (2015). Condoning Stereotyping? How Aware- 
ness of Stereotyping Prevalence Impacts Expression of Stereotypes. Journal of Applied Psychology, 100, 343-359. https://doi.apa.org/doi/10.1037/a0037908

Epstein, S. (1994). Integration of the Cognitive and the Psychodynamic Unconscious. American Psychologist, 49, 709-724.

https://doi.apa.org/doi/10.1037/0003-066X.49.8.709

Fisher, L. (2020). Exclusive: Unconscious Bias Training to Be Scrapped after Review FindsIt Has Little Effect. Telegraph UK.

https://www.telegraph.co.uk/politics/2020/12/14/exclusive-unconscious-bias-training-s crapped-review-finds-has/

FitzGerald, C., Martin, A., Berner, D., \& Hurst, S. (2019). Interventions Designed to Reduce Implicit Prejudices and Implicit Stereotypes in Real World Contexts: A Systematic Review. BMC Psychology, 7, Article No. 29.

https://doi.org/10.1186/s40359-019-0299-7

Forbes (2020). Why UK Ministers Should Rethink Their Decision to End Unconscious Bias Training.

https://www.forbes.com/sites/frankstarling/2020/12/18/why-uk-ministers-should-rethi nk-their-decision-to-end-unconscious-bias-training/?sh $=11824 \mathrm{cce} 658 \mathrm{c}$

Forrest, A. (2020). Boris Johnson's government scraps unconscious bias training for civil servants. Independent UK. Retrieved, 15 December, 2020.

https://www.independent.co.uk/news/uk/politics/boris-johnson-unconscious-bias-trai ning-b1774154.html

Gawronski, B. (2019). Six Lessons for a Cogent Science of Implicit Bias and Its Criticism. Perspectives on Psychological Science, 14, 574-595.

https://doi.org/10.1177\%2F1745691619826015

Gawronski, B., Morrison, M., Phills, C. E., \& Galdi, S. (2017). Temporal Stability of Implicit and Explicit Measures: A Longitudinal Analysis. Personality and Social Psychology Bulletin, 43, 300-312. https://doi.org/10.1177\%2F0146167216684131

Gigerenzer, G. (1991). How to Make Cognitive Illusions Disappear: Beyond "Heuristics and Biases". European Review of Social Psychology, 2, 83-115.

https://doi.org/10.1080/14792779143000033

Government UK (2020). Written Ministerial Statement on Unconscious Bias Training. Government UK, Cabinet Office. Retrieved, 17, December, 2020.

https://www.gov.uk/government/news/written-ministerial-statement-on-unconsciousbias-training

Greenwald, A. G., McGhee, D. E., \& Schwartz, J. L. K. (1998). Measuring Individual Differences in Implicit Cognition: The Implicit Association Test. Journal of Personality and Social Psychology, 74, 1464-1480. https://doi.apa.org/doi/10.1037/0022-3514.74.6.1464

Jost, J. T. (2019). The IAT Is Dead, Long Live the IAT: Context-Sensitive Measures of Implicit Attitudes Are Indispensable to Social and Political Psychology. Current Directions in Psychological Science, 28, 10-19. https://doi.org/10.1177\%2F0963721418797309

Kahneman, D. (2011). Thinking, Fast and Slow. London: Macmillan.

Karelse, J. (2021). Mitigating Unconscious Bias in Forecasting. Foresight: The International Journal of Applied Forecasting, 61, 5-14.

Kirkland, R., \& Bohnet, I. (2017). Focusing on What Works for Workplace Diversity. Chicago, IL: McKinsey and Company.

https://www.mckinsey.com/featured-insights/gender-equality/focusing-on-what-works 
-for-workplace-diversity

Newell, B. R., \& Shanks, D. R. (2014). Unconscious Influences on Decision Making: A Critical Review. Behavioral and Brain Sciences, 37, 1-19.

https://doi.org/10.1017/S0140525X12003214

Newkirk, P. (2019). Diversity, Inc.: The Failed Promise of a Billion-Dollar Business. UK: Hachette.

Noon, M. (2018). Pointless Diversity Training: Unconscious Bias, New Racism and Agency. Work, Employment and Society, 32, 198-209. https://doi.org/10.1177\%2F0950017017719841

Osman, M. (2014). Future-Minded: The Psychology of Agency and Control. London: Macmillan International Higher Education.

Oswald, F. L., Mitchell, G., Blanton, H., Jaccard, J., \& Tetlock, P. E. (2013). Predicting Ethnic and Racial Discrimination: A Meta-Analysis of IAT Criterion Studies. Journal of Personality and Social Psychology, 105, 171-192. https://doi.apa.org/doi/10.1037/a0032734

Oswald, F. L., Mitchell, G., Blanton, H., Jaccard, J., \& Tetlock, P. E. (2015). Using the IAT to Predict Ethnic and Racial Discrimination: Small Effect Sizes of Unknown Societal Significance. Journal of Personality and Social Psychology, 108, 562-571. https://doi.org/10.1037/pspa0000023

Oswick, C., \& Noon, M. (2014). Discourses of Diversity, Equality and Inclusion: Trenchant Formulations or Transient Fashions? British Journal of Management, 25, 23-39. https://doi.org/10.1111/j.1467-8551.2012.00830.x

Rezaei, A. R. (2011). Validity and Reliability of the IAT: Measuring Gender and Ethnic Stereotypes. Computers in Human Behavior, 27, 1937-1941. https://doi.org/10.1016/j.chb.2011.04.018

Sayal, R. (2020). UK Ministers Criticised for Failing to Find Alternative to Unconscious Bias Training' Guardian UK. Retrieved 15, December, 2020.

https://www.theguardian.com/politics/2020/dec/15/uk-ministers-criticised-for-failing-t o-find-alternative-to-unconscious-bias-training

Skov, T. (2020). Unconscious Gender Bias in Academia: Scarcity of Empirical Evidence. Societies, 10, Article No. 31. https://doi.org/10.3390/soc10020031 